\title{
The influence of electrode infeed in finishing wire electrical discharge machining process on disks fir tree slot accuracy
}

\author{
Wpływ dosuwu elektrody w wykończeniowej obróbce WEDM \\ na parametry jakościowe zamka wirnika
}

\section{JAN BUREK \\ ROBERT BABIARZ \\ MARCIN PŁODZIEŃ \\ JAROSŁAW BUK *}

The article presents the effect of electrode infeed in finishing machining of disk fir tree slots made of Inconel 718 alloy on shape accuracy and surface roughness in WEDM (wire electrical discharge machining).

KEYWORDS: WEDM, profile deviation, surface roughness, fir tree slot

A common method of turbine disk's fir tree slot machining is broaching. Due to the high costs of tools and broaching machines, long time of tools designing and manufacturing and necessity to resharpening and recoatings, alternative methods of fir tree slots machining in turbine disks are still being researched [1-4]. One of those methods is wire electrodischarge machining WEDM. Its application in production of responsible machine parts is currently the subject of many research works. This method allows a significant reduction in production costs and increase production flexibility due to the use of a universal tool, such as thin wire, and simple machine programming [2-5].

The accuracy of the WEDM machining depends largely on the vibrations and deflection of the electrode caused by the forces accompanying the erosion process. The reduction of the forces impact on the shape accuracy can be obtained in additional, finishing passes of wire electrodes [2, 6-8].

The purpose of this research was to determine the effect of electrode infeed on shape accuracy and surface roughness in finishing fir tree slot machining made of Inconel 718 alloy.

\section{Fir tree slots WEDM machining}

The turbine rotor is made of blades and a turbine disc (fig 1). The blades are fixed in the disc by fir tree slots. Typical fir tree slots have from two to seven protrusions, while in aerospace applications - two or three pairs usually.

\footnotetext{
* Dr hab. inż. Jan Burek, prof. PRz (jburek@prz.edu.pl), dr inż. Rober Babiarz (robertb@prz.edu.pl), dr inż. Marcin Płodzień (plodzien@prz. edu.pl), mgr inż. Jarosław Buk (jbuk@prz.edu.pl) - Katedra Technik Wytwarzania i Automatyzacji, Wydział Budowy Maszyn i Lotnictwa Politechniki Rzeszowskiej
}

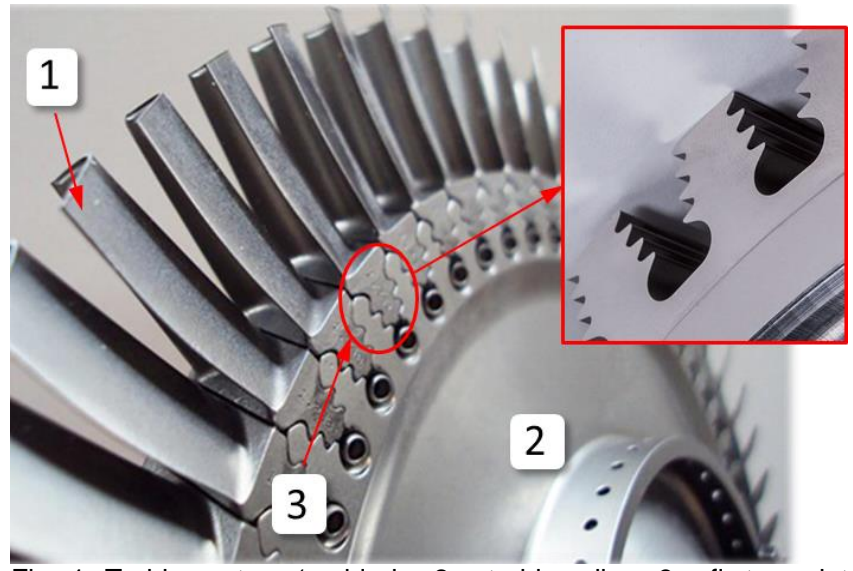

Fig. 1. Turbine rotor: 1 - blade, 2 - turbine disc, 3 - fir tree slot $[9,10]$

The surface of fir tree slot (fig. 2) is most often a ruled surface, which allows it to be machined by using WEDM cutting method. The first characteristic line is the profile of fir tree slot, while the second is the fir tree slot line. The machining accuracy requirements apply to the profile and the line of fir tree slot.

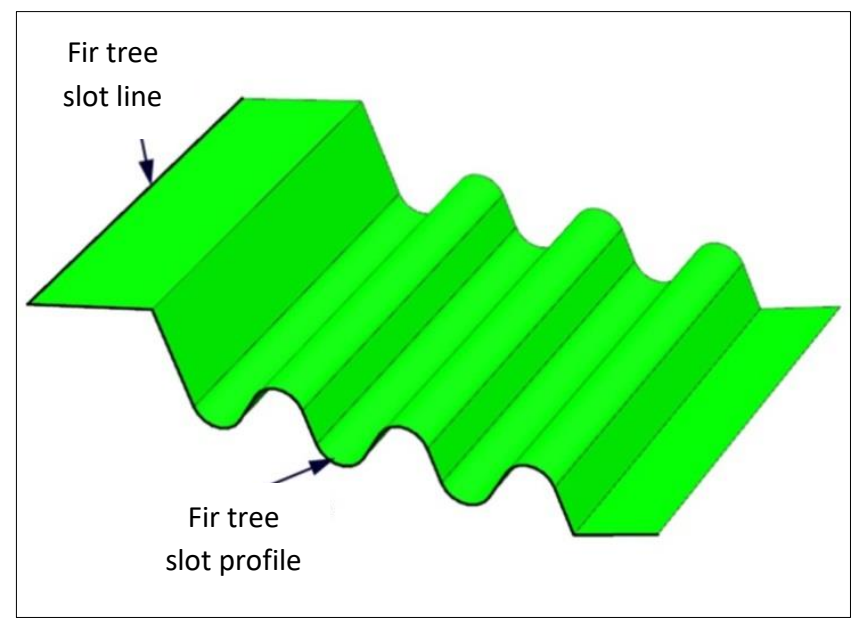

Fig. 2. Profile and line of fir tree slot 
In the WEDM machining there are four types of forces acting on the electrode, which cause its vibration and deflection, and as a consequence - machining errors. Those forces are: discharge reactions forces, electrostatic force, hydrodynamic force and electromagnetic force [2, 6, 8]. Two forces act during the discharge: discharge reactions forces and the electrodynamic force. The electrostatic force occurs in the gap between the discharges, while the hydrodynamic force influence is still present.

\section{Research conditions}

The tool was a brass wire electrode with $\varnothing 0.25 \mathrm{~mm}$ diameter. The samples were made in the form of one side of fir tree slot (fig. 3). The width of the slot (workpiece height) was $30 \mathrm{~mm}$.

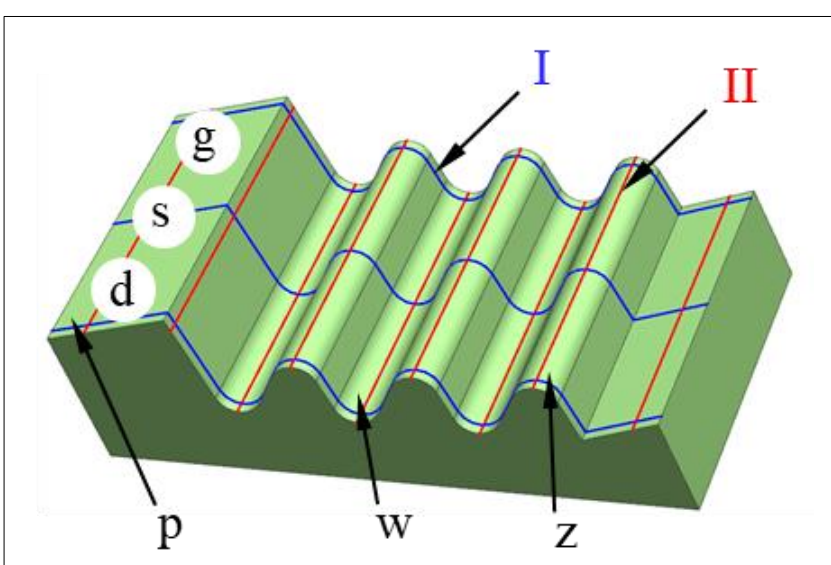

Fig. 3. Fir tree slot with marked measuring grid (parts of the sample: $\mathrm{d}$ - lower, $\mathrm{s}$ - middle, $\mathrm{g}$ - upper, $\mathrm{p}$ - flat surface, $w$ - inner radius, $z$ - outer radius, $\mid-$ profile measuring path, II - measuring path of the slot line)

Measurements of profile deviations $\Delta k$ and line deviations $\Delta p$ were made on the Mahr XC20 contourograph. The measuring lines of the profile deviations are marked with blue color. Three paths were determined at equal distances over the entire width of the slot: in the lower part (d), in the middle (s) and in the upper part $(\mathrm{g})$. Line deviations were measured in the normal-to-feed direction and are marked in red. Measurements were made on straight surfaces $(p)$, outer radius $(z)$ and inner radius $(w)$. The obtained profiles were compared with the nominal profile generated from the CAD model. Measurement of deviations of the profile and the slot line was carried out five times for each measuring path.

The samples were made in the technology provided by the WEDM machine manufacturer for the group of steel materials [11]. In the first pass, rough cutting was carried out and in the second pass finishing cutting was carried out using a variable value of the infeed parameter $z=5 \div 60 \mu \mathrm{m}$ with step of $5 \mu \mathrm{m}$. The machining parameters are given in the table.

\section{TABLE. Machining parameters}

\begin{tabular}{|c|c|c|}
\hline Machining pass & $\begin{array}{c}1 \\
\text { (rough cut) }\end{array}$ & $\begin{array}{c}2 \\
\text { (finish cut) }\end{array}$ \\
\hline $\begin{array}{c}\text { Average value of discharge } \\
\text { voltage } U_{c}, \mathrm{~V}\end{array}$ & 43 & 57 \\
\hline $\begin{array}{c}\text { Current peak during } \\
\text { discharge } I_{c}, \mathrm{~A}\end{array}$ & 170 & 179 \\
\hline Break time $t_{\text {off }}, \mu \mathrm{s}$ & 24 & 14 \\
\hline Tension of the wire $F_{\mathrm{n}}, \mathrm{N}$ & 15 & 19 \\
\hline Feedrate $f, \mathrm{~mm} / \mathrm{min}$ & 2,5 & 4,8 \\
\hline Dielectric flow rate $Q_{v}, \mathrm{I} / \mathrm{min}$ & $\geq 10$ & $\sim 1.4$ \\
\hline
\end{tabular}

The machining was carried out on a Mitsubishi FA10S wire electro-discharge cutting machine (fig. 4). The current and voltage waveforms were recorded using the Hioki CT6843 current probe, Rigol RP1300H voltage probe and the Rigol DS1074Z oscilloscope. The cutting process was performed in immersion in dielectric - demineralized water. The positioning error of the machine was $1 \mu \mathrm{m}$.

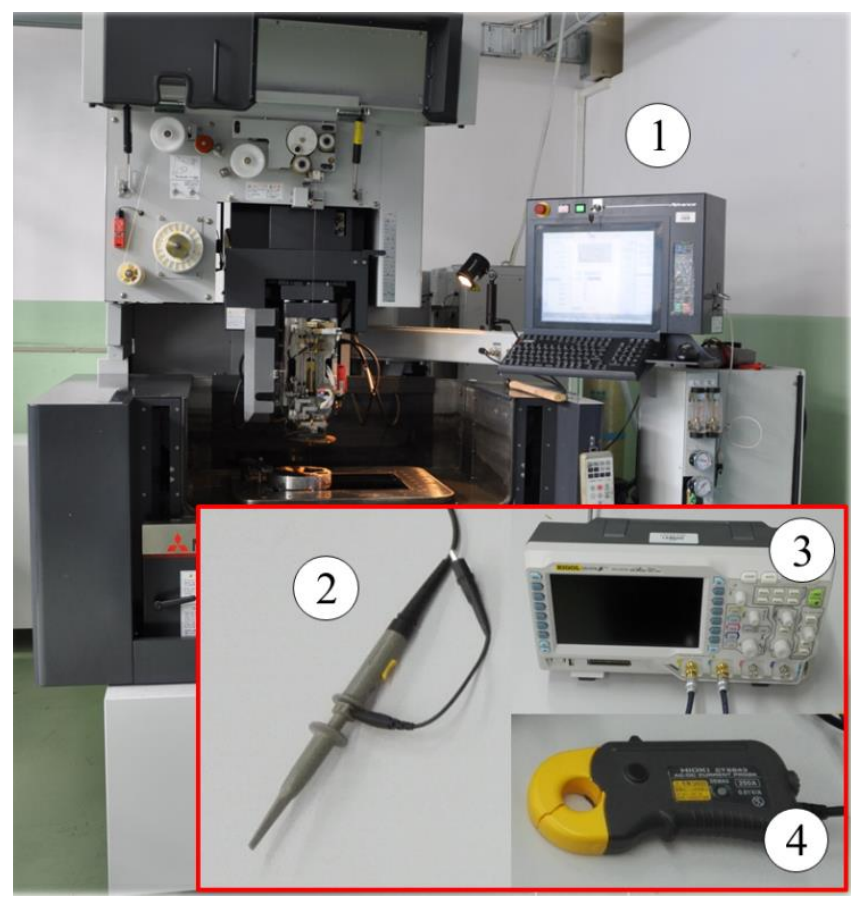

Fig. 4. Research stand: 1 - Mitsubishi FA10S WEDM cutting machine, 2 - Rigol RP1300H voltage probe, 3 - Rigol DS1074Z oscilloscope, 4 - Hioki CT6843 current probe

\section{Measurements}

The shape deviations $\Delta k$ and rectilinearity deviations $\Delta p$ of the measured profiles are shown in fig. 5 and fig. 6 .

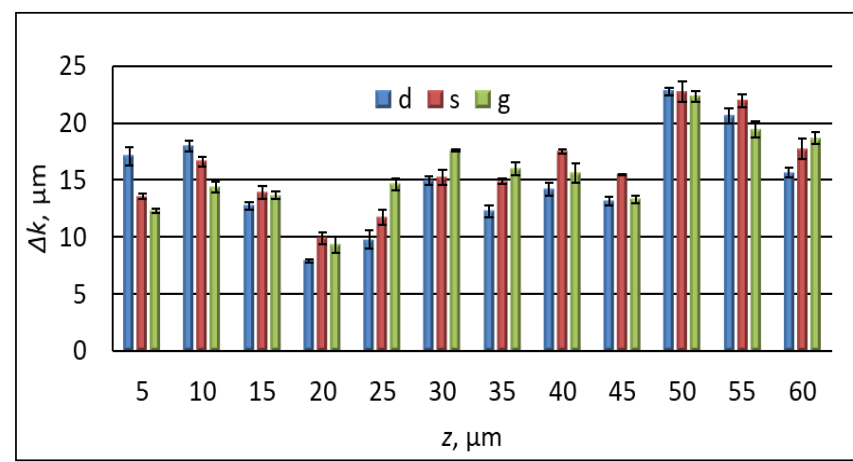

Fig. 5. Fir tree slot profile deviations $\Delta k$ (parts of the sample: $d-$ lower, $\mathrm{s}$ - middle, $\mathrm{g}$ - upper) depending on the infeed $z$

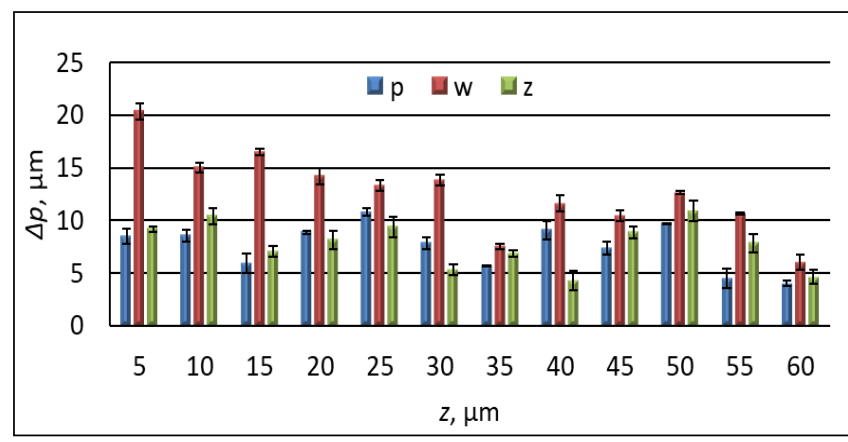

Fig. 6. Fir tree slot line deviations $\Delta p$ (parts of the sample: $p$ - flat surfaces, $\mathrm{w}$ - inner radii, $\mathrm{z}$ - outer radii) depending on the infeed $z$ 
In the infeed range $z=5 \div 45 \mu \mathrm{m}, \Delta k$ deviations had a similar value - from approx. $13 \mu \mathrm{m}$ to $17 \mu \mathrm{m}$. The exceptions were deviations for infeed $z=20 \mu \mathrm{m}$, which were below $10 \mu \mathrm{m}$ and were the smallest of all measurements. A significant increase in the deviation values can be seen for infeed $z=50 \mu \mathrm{m}$ and larger.

For infeed from the range $z=5 \div 30 \mu \mathrm{m}$, deviations $\Delta p$, measured at inner radius, are higher than on flat surfaces and outer radius. For subsequent infeeds, those differences are much smaller. The lowest deviation values were measured for infeed $z=35 \mu \mathrm{m}$ and $z=60 \mu \mathrm{m}$.

Straightness deviations $\Delta p$ on the outer and inner radius take the form of hourglass (fig. 7a). When comparing the lowest straightness deviations obtained with infeed $z=35 \mu \mathrm{m}$ and $z=60 \mu \mathrm{m}$, it can be seen that for the infeed $z=35 \mu \mathrm{m}$, the electrode deflection occurred during radii machining. Only for the infeed $z=60 \mu \mathrm{m}$ the distribution of deviations on the radii was regular (fig. $7 b$ ).

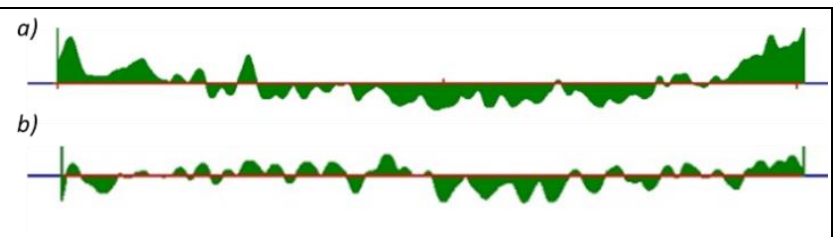

Fig. 7. Distribution of straightness deviations $\Delta p$ on the inner radius for infeed: a) $z=35 \mu \mathrm{m}$, b) $z=60 \mu \mathrm{m}$

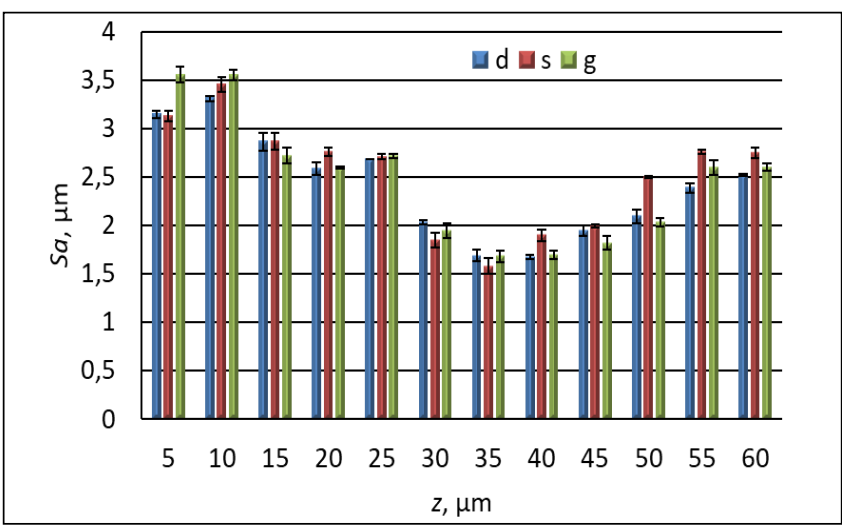

Fig. 8. Surface roughness $S a$ of the tested samples (parts of the sample: $d$ - lower, $s$ - middle, $g$ - upper) depending on the infeed $z$

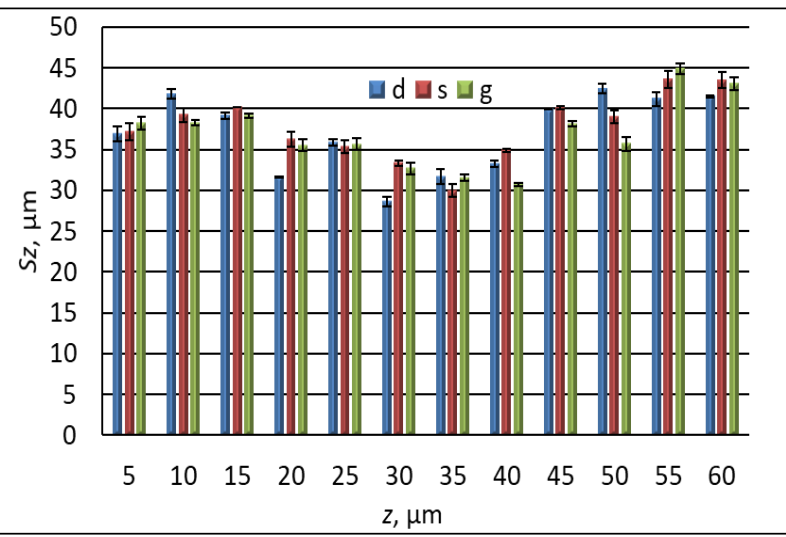

Fig. 9. Highest surface height $S z$ of the tested samples (parts of the sample: $\mathrm{d}$ - lower, $\mathrm{s}$ - middle, $\mathrm{g}$ - upper) depending on the infeed $z$

Surface roughness measurements were made on the Infinite Focus microscope of Alicona. They were repeated five times in each mentioned area $(d, s, g)$. The results of measurements of surface roughness parameters $S a$ and $S z$ are shown in fig. 8 and fig. 9.

The lowest values of the surface roughness $S a$ were measured for the infeed $z=35 \mu \mathrm{m}$. Both increasing and decreasing the infeed increased the value of the parameter Sa. A similar tendency was noted for the parameter Sz. Its lowest values were obtained for infeed in the range of $z=30 \div 40 \mu \mathrm{m}$.

\section{Conclusions}

Smaller infeed values resulted in machining on an incomplete workpiece height. For the infeed in the range of $z$ $=5 \div 10 \mu \mathrm{m}$, there were only a few erosion processes in the finishing cutting path. On inner radius, the values of straightness deviations increased in comparison to flat surfaces and outer radius. Deviations on the radius took a characteristic distribution in the form of hourglass. The exception was the sample made with the infeed $z=60 \mu \mathrm{m}-$ in this case the distribution of deviations was regular. For this infeed value, the minimum deflection of the electrode was obtained.

Infeeds from the range of $z=30 \div 40 \mu \mathrm{m}$ allowed to reduce the value of $S a$ and $S z$ parameters. The lowest values have been obtained for the infeed $z=35 \mu \mathrm{m}$. Infeed from $40 \div 60$ $\mu \mathrm{m}$ caused an increase in the values of $S a$ and $S z$ parameters. Above $z=60 \mu \mathrm{m}$ there were short-circuits between the electrode and the workpiece, which made machining impossible.

In the finishing cutting path, the erosion processes and accompanying phenomena occur mainly in the normal-tofeed direction, on one side of the electrode. The change in infeed affects the force values during erosion and, consequently, also the machining accuracy.

\section{REFERENCES}

1. Klocke F., Vogtel P., Gierlings S., Lung D., Veselovac D. "Broaching of Inconel 718 with cemented carbide". German Academic Society for Production Engineering (WGP). 7 (2013): pp. 593-600.

2. Klocke F., Welling D., Klink A., Perez R. "Quality assessment through in-process monitoring of wire-EDM for fir tree slot production". Procedia CRIP. 24 (2014): pp. 97-102.

3. Sharma P., Chakradhar D., Narendranath S. "Evaluation of WEDM performance characteristics of Inconel 706 for turbine disk application". Materials and Design. 88 (2015): pp. 558-566.

4. Klocke F., Welling D., Klink A., Veselovac D., Nöthe T., Perez R. "Evaluation of advanced wire-EDM capabilities for the manufacture of fir tree slots in Inconel 718". Procedia CRIP. 14 (2014): pp. 430-435.

5. Oniszczuk-Świercz D., Świercz R., Dąbrowski L., Marczak M. „Konstytuowanie warstwy wierzchniej Inconelu 718 po wycinaniu elektroerozyjnym". Mechanik. 4 (2015): pp. 71-74.

6. Puri A.B., Bhattacharyya B. "An analysis and optimisation of the geometrical inaccuracy due to wire lag phenomenon in WEDM". International Journal of Machine Tool \& Manufacure. 43 (2003): pp. 151-159.

7. Liang J.F., Tsai C.F., Lin M.H., Liao Y.S. "Measurement of wire deflection in wire - cut EDM machining". ISEM 2010, pp. 223-226.

8. Dekeyser W.L., Snoeys R. "Geometrical accuracy of WireEDM”. Proc. of ISEM. 9 (1989): pp. 226-232.

9. www.turbineenginesolutions.com.

10. www.gfms.com.

11. Mitsubishi Electric Corporation, Wire-Cut EDM Systems, FA-S Advance Series machining characteristics data book, BQN-W70538C, version 3.0, 2010.

Translation of scientific articles, their computer composition and publishing them on the website www.mechanik.media.pl by original articles in Polish is a task financed from the funds of the Ministry of Science and Higher Education designated for dissemination of science.

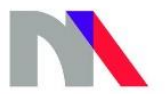
and Higher Education 